\title{
Study of Causes of Film Formation on the Electrolyte Surface During Niobium Electrorefining
}

\author{
I. B. Polovov ${ }^{\mathrm{a}}$, M. V. Chernyshov ${ }^{\mathrm{a}}$, O. I. Rebrin', V. A. Volkovich, \\ M. G. Shtutsa ${ }^{b}$, and T. R. Griffiths ${ }^{c}$ \\ ${ }^{a}$ Department of Rare Metals, Ural State Technical University-UPI, Ekaterinburg, \\ 620002, Russia \\ ${ }^{\mathrm{b}}$ JSC Chepetsky Mechanical Plant, Glazov, 427620, Russia \\ ${ }^{\mathrm{c}}$ Redston Trevor Consulting, Ltd., Leeds, LS17 8RF, UK
}

Formation of a conducting film on the surface of fused electrolyte during electrorefining of niobium in chloride melts was investigated. It was found that this film has metallic nature and is formed as a result of disproportionation of niobium(III) ions at a liquid-gas interface. Decreasing temperature gradient along the heated part of the electrolyser can be used to limit the influence of the disproportionation onto film formation. The metal film formation on solid ceramics can be used for creation of conducting layers on various oxide materials.

\section{Introduction}

Alkali halide melts, particularly those based on the equimolar mixture of sodium and potassium chlorides are widely used as working media for metal electrorefining. One of the potential disadvantages of such process is a formation during electrolysis of a solid conducting film between the anode and the cathode that eventually causes a short circuit. Prevention or limitation of the formation of such film is an important task for developing electrolytic methods of metal production.

Previously such film formation was observed in halide baths with soluble anodes when the electrolysis was conducted under an inert atmosphere. Formation of a film shortening cathode and anode was reported during electrorefining of titanium $(1,2)$, zirconium (3), molybdenum (4, 5), rhenium (6), aluminium (7) and hafnium (8). Apparently, the presence of such films is typical for the elements forming higher volatile chlorides. In the present work the formation of a conducting film was detected during electrorefining of niobium in $\mathrm{NaCl}-\mathrm{KCl}$ based melts. We attempted to explain the reasons for the film formation and find the conditions of the electrolysis preventing the formation of such film.

Available literature describes three principally different mechanisms of the film formation. According to the first (2) a very thin film of a metal or a some compound having electronic conductivity is formed on the melt surface as a result of disproportionation or an exchange reaction even before the current is applied. The second mechanism $(4,9)$ does not assume the presence of a primary film; an excessive concentration of lower oxidation state metal ions is formed during the cathodic reaction due to some difficulties in reduction of this ions to the metallic state. Lower oxidation state metal ions diffuse away from the cathode and disproportionate at the liquid-gas interface that catalyses nucleation of the metal crystals. The third mechanism (8) is based 
on the reactions of anion disproportionation occurring between oxide material of the melt container and lower metal chlorides, and resulting in the formation of the solid film and also some oxychloride species. It was also suggested (8) that impurities in the atmosphere (an insufficient purity of an inert gas) above the melt results in the same phenomenon.

\section{Experimental}

The experiments on niobium elecrtorefining were conducted in a large-scale stainless steel water-cooled laboratory electrolyser (Fig. 1). Starting metal was placed into a special anodic basket made of molybdenum wire.

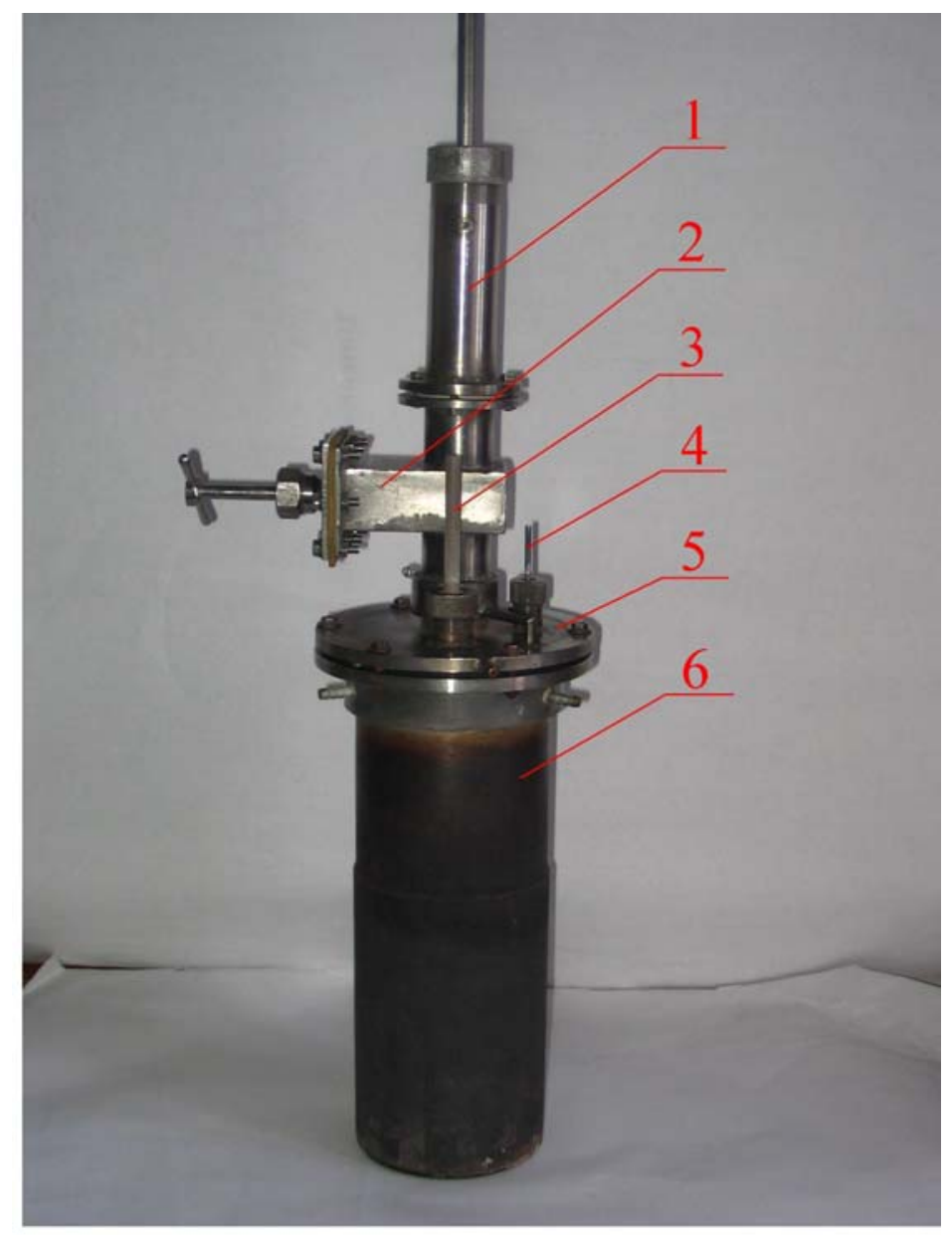

Figure 1. Semi-industrial electrolyser for niobium electrorefining ( 1 - cathode assembly, 2 - slide valve, 3 - thermocouple sheath, 4 - anode basket current conductor, 5 - water cooled lid, 6 - steel retort).

Niobium containing melt was prepared by "dry" chlorination of niobium (10) and then held in the contact with metallic niobium (99.8 \% pure, JSC ChMP) for 10-15 hours until niobium electrode potential became equal to the potential of a glassy carbon indicator electrode. Quenched melt was separated from remaining metal in an inert atmosphere dry box and loaded into the crucible container (made of SU-2000 glassy carbon) of the electrolyser in the form of 50-70 $\mathrm{mm}$ pieces. 
After loading the electrolyser was evacuated and 2-3 times flushed with argon. The atmosphere in the apparatus was dry purified argon. Argon was purified by slowly passing the gas above iodide refined zirconium turnings at $800{ }^{\circ} \mathrm{C}$. Additional purification of the atmosphere was achieved by placing metallic niobium powder (acting as a getter) onto the bottom of the apparatus.

The electrolyser was heated in a vertical tube furnace controlled by a high precision temperature regulator. After the salt was melted the anodic basket followed by a silica thermocouple sheath, with a K-type thermocouple, were lowered into the melt.

After the temperature reached required value the thermocouple was lifted the cathode assembly (consisting of stainless steel lid, insulating gaskets, and molybdenum cathode on a stainless steel rod with connecting molybdenum wire) was put in place. Using molybdenum wire for connecting Mo cathode with the steel rod allowed to minimise heat loos from the melt surface through this supporting rod. The cathode assembly was evacuated and 2-3 times flushed with argon; after that the slide valve 2 in Fig. 1 was opened, the cathode lowered into the melt and current switched on. The following parameters were controlled during the experiments: amount of electricity passed, voltage on the bath, and electrode potential at switched off current.

After the required amount of electricity was passed through the melt, the current was switched off, the cathode carefully lifted from the melt into the cathode assembly (that was constantly air cooled), the slide valve was closed and the cathode assembly disassembled. The electrode with the deposit was disconnected, photographed, weighed and treated following the previously developed procedure (11). After the used cathode was removed a new one was positioned into the cathode assembly, the latter again evacuated and flushed with argon, and then the new cathode was lowered into the melt. After the required number of the electrolysis cycles was completed, the anode basket was lifted from the melt, the furnace switched off and the melt quenched in the crucible.

\section{Results and discussion}

It has been previously shown (12) that in niobium containing $\mathrm{NaCl}-\mathrm{KCl}$ based melts contacted with metallic $\mathrm{Nb}$ niobium is present as a mixture of tri- and tetravalent ions. The same work contains the values of cathodic and anodic current efficiencies obtained from the analysis of the results on niobium electrorefining in chloride melts. We here expected that the average oxidation state of niobium and current efficiencies would correspond to the previously obtained data (12). Anodic and cathodic current efficiencies obtained here are presented in Table I. These values (expts. 1-8 in Table I) differ from one experiment to another and there is no apparent connection of changes of current efficiencies and experimental conditions. We can logically assume that the low current efficiencies are not connected with the electrode processes mechanisms but are explained by some unforeseen methodical errors that appeared when we moved from a large-scale laboratory apparatus to a semi-industrial one. The values of the anodic and cathodic current efficiency are connected with each other, when low anodic current density was observed the cathodic current density was also low, and vice versa, Table I. 
In our opinion such low values of the current efficiency and higher than expected average oxidation state of niobium can be explained by the formation of a solid conducting film on the melt surface. This film can cause shortening of the anode and cathode, after that electric current simply flows through this film and is not spent onto dissolution of niobium at the anode and deposition of the cathode product.

\begin{tabular}{ccccc}
\multicolumn{6}{c}{ TABLE I. Current efficiency during niobium electrorefining in $\mathrm{NaCl}-\mathrm{KCl}$-based melts at $730^{\circ} \mathrm{C}$} \\
\hline $\begin{array}{c}\text { Exp. } \\
\text { No. }\end{array}$ & $\begin{array}{c}\text { Cathodic current } \\
\text { efficiency, } \mathbf{g} /(\mathbf{A} \cdot \mathbf{h})\end{array}$ & $\begin{array}{c}\text { Anodic current } \\
\text { efficiency, } \mathbf{g} /(\mathbf{A} \cdot \mathbf{h})\end{array}$ & $\begin{array}{c}\text { Nb oxidation state } \\
\text { determined from cathodic } \\
\text { current efficiency }\end{array}$ & $\begin{array}{c}\text { Nb oxidation state } \\
\text { determined from anodic } \\
\text { current efficiency }\end{array}$ \\
\hline 1 & 0.48 & 0.78 & 7.22 & 4.44 \\
2 & 0.58 & 0.65 & 5.98 & 5.33 \\
3 & 0.74 & 0.85 & 4.68 & 4.07 \\
4 & 0.61 & 0.65 & 5.68 & 5.33 \\
5 & 0.60 & 0.71 & 5.78 & 4.88 \\
6 & 0.17 & 0.25 & 20.39 & 13.86 \\
7 & 0.48 & 0.69 & 7.22 & 5.02 \\
8 & 0.50 & 0.64 & 6.93 & 5.42 \\
$9^{*}$ & 0.91 & 0.97 & 3.81 & 3.57 \\
$10^{*}$ & 0.85 & 0.87 & 4.08 & 3.98 \\
$11^{*}$ & 0.84 & 0.96 & 4.13 & 3.61 \\
$12^{*}$ & 0.85 & 1.07 & 4.08 & 3.24 \\
\hline
\end{tabular}

* - working temperature $-780{ }^{\circ} \mathrm{C}$

A special series of the experiments was performed in order to determine the nature of this conducting film, causes of its formation and possible ways of avoiding such negative phenomenon.

First we investigated an assumption that this film is formed due to a temperature gradient between the surface and the bulk of the melt. The surface layer of the melt has normally somewhat lower temperature than the bulk, and therefore, according to the temperature dependencies of most of the equilibrium constants of the reactions involving a metal and its ions in two different oxidation states (2), the electrolyte, existing in the equilibrium with the metal in the bulk of the melt, will contain a larger than the equilibrium amount of the lower oxidation state ions, than in the near surface colder part. Disproportionation of the lower oxidation state ions would result in the formation of the metal. However, prolonged 14 hours contact of niobium containing melt with metallic niobium in a glassy carbon crucible did not lead to the formation of any film on the melt surface.

Then we investigated the possibility that the film is formed as a result of a reaction of anionic disproportionation initiated by the contact with oxygen containing ceramic materials. A massive silica tube was lowered in to the melt contained metallic niobium. No film was formed on the melt surface after 14 hours contact. However a layer of a metal-like substance was formed on the surface of the silica tube itself (Fig. 2). This indicates occurrence of either the reaction of the anionic disproportionation (8):

$$
8 \mathrm{NbCl}_{3}+3 \mathrm{SiO}_{2}=6 \mathrm{NbOCl}_{2}+3 \mathrm{SiCl}_{4}+2 \mathrm{Nb}
$$

or certain red-ox reactions leading to the formation of niobium silicides or silica monoxide: 


$$
\begin{array}{r}
12 \mathrm{NbCl}_{3}+2 \mathrm{SiO}_{2}=\mathrm{NbSi}_{2}+4 \mathrm{NbOCl}_{2}+7 \mathrm{NbCl}_{4} \\
32 \mathrm{NbCl}_{3}+3 \mathrm{SiO}_{2}=\mathrm{Nb}_{5} \mathrm{Si}_{3}+6 \mathrm{NbOCl}_{2}+21 \mathrm{NbCl}_{4} \\
2 \mathrm{NbCl}_{3}+\mathrm{SiO}_{2}=\mathrm{SiO}+\mathrm{NbOCl}_{2}+\mathrm{NbCl}_{4}
\end{array}
$$

The metal-like layer formed on the surface of the silica tube conducts electricity although its conductivity several times less than that of $1 \mathrm{~mm}$ thick niobium foil.

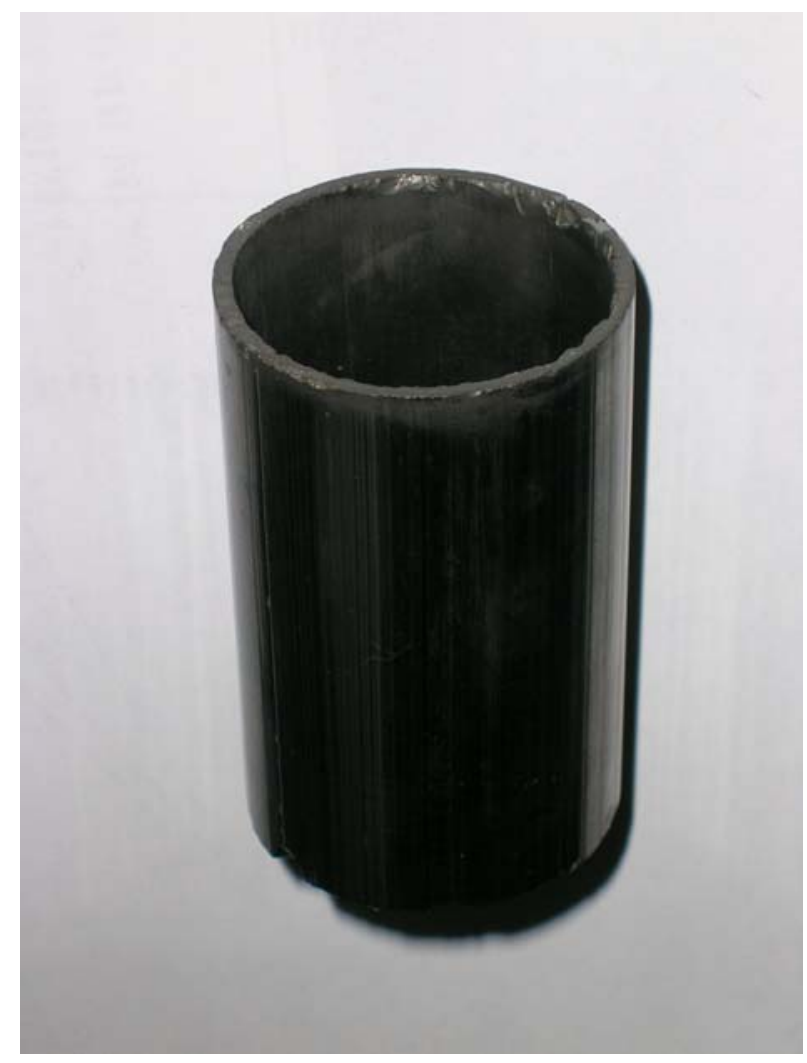

Figure 2. Metallization of quartz tube after $14 \mathrm{~h}$ contact with niobium containing melt.

Thus no formation of thin conducting films on the melt surface was observed in the absence of the applied current in pure niobium containing melt, and in the melt contacted with oxide ceramics and metallic niobium.

From the other side, when the current was applied between the anode and the cathode fully submerged into the melt, and if the current conducting wires were not shielded from the contact with the melt, this solid film on the melt surface was formed fairly quickly and in some experiments its thickness reached $2-3 \mathrm{~mm}$. Attempts to shield the current conducting wires from the electrolyte using insulating tubes lowered into the melt were not successful. A variety of materials (aluminium and beryllium oxides, silica and boron nitride) were tested but eventually surface of all of them became metallic, and this metallic layer was spreading upwards from the point where the insulating tube touched the niobium electrode.

The longer the electrolysis was carried out for at a given current density the greater surface of the melt was covered by the film. Reducing cathodic current density leads to 
the same result. This data agree well with the findings of Baraboshkin et al. (4) studied elelctrorefining of molybdenum.

The morphology of niobium deposits on the film is the same as the deposit formed on the cathode. Spherical niobium particles are formed during the growth of the deposit. Upper side of the film (contacted with the gas phase) consists of many small undirected crystals (Fig. 3a). Lower side of the film (directed to the melt) consists of larger particles (Fig. 3b). The particles grow in the direction from the surface down to the bulk of the melt, this can be seen both on the film cross-section (in a moment of beginning of niobium film growth) and on the deposit formed on the film (Fig. 3c).

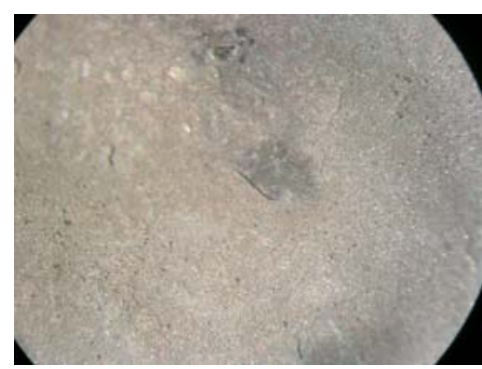

a). Upper part of the film

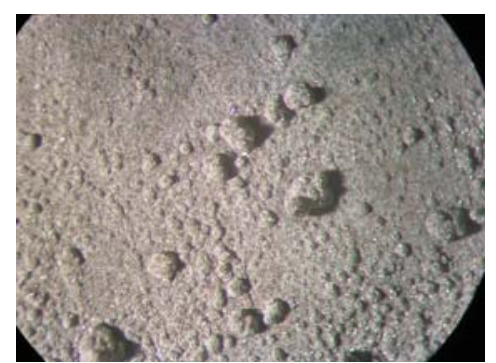

b). Lower part of the film

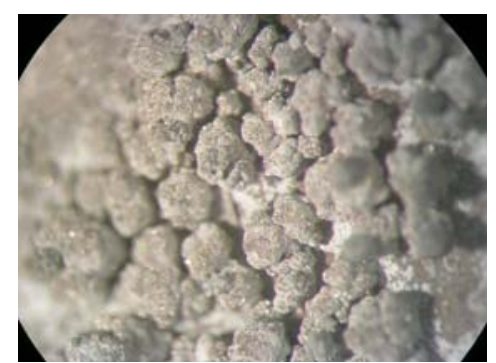

c). Growing niobium deposit on the film

Figure 3. Morphology of the film (enlargement: x20)

X-ray powder diffraction analysis showed that the surface film mainly consisted of metallic niobium and contained some trapped $\mathrm{NaCl}-\mathrm{KCl}$. Chemical and repeated $\mathrm{X}$-ray analysis of washed samples of the film confirmed that the remaining solid contained 95$98 \%$ niobium.

We can therefore conclude that the film on the melt surface mainly consists of niobium metal and is formed as a result of disproportionation of lower oxidation state niobium ions, i.e., $\mathrm{Nb}(\mathrm{III})$ :

$$
4 \mathrm{Nb}^{3+} \Leftrightarrow 3 \mathrm{Nb}^{4+}+\mathrm{Nb}
$$

Chemical and X-ray diffraction analyses of the quenched melt samples confirmed the presence of fine niobium metal particles in the bulk of the melt. The difference between the anodic and cathodic current efficiencies indicates that more niobium dissolves from the anode than is deposited on the cathode. Nevertheless niobium concentration in the electrolyte gradually decreases confirming disproportionation of $\mathrm{Nb}$ (III) species. It is likely that the reaction [5] predominantly takes place at the liquid melt - gas interface. A larger than the equilibrium concentration of $\mathrm{Nb}$ (III) ions formed during the anodic dissolution shifts the equilibrium of the reaction [5] to the right.

Catalytic-like properties of melt surface were previously explained by the adsorption of solid particles of various impurities (5). From our point of view a catalytic role of "gas-electrolyte" interface can be explained by the temperature gradient between the melt surface and the bulk of the electrolyte. As a result the equilibrium [5] increasingly shifted to the right. 
To determine the cause of the catalytic effect of the electrolyte surface we measured the temperature gradient along the heated part of the electrolyser, Fig. 4. The plot contains a well pronounced inflection (temperature suddenly changes by over 50 degrees) corresponding to the melt surface. Under such non-equilibrium conditions the possibility of disproportionation of lower oxidation state niobium ions cannot be excluded.

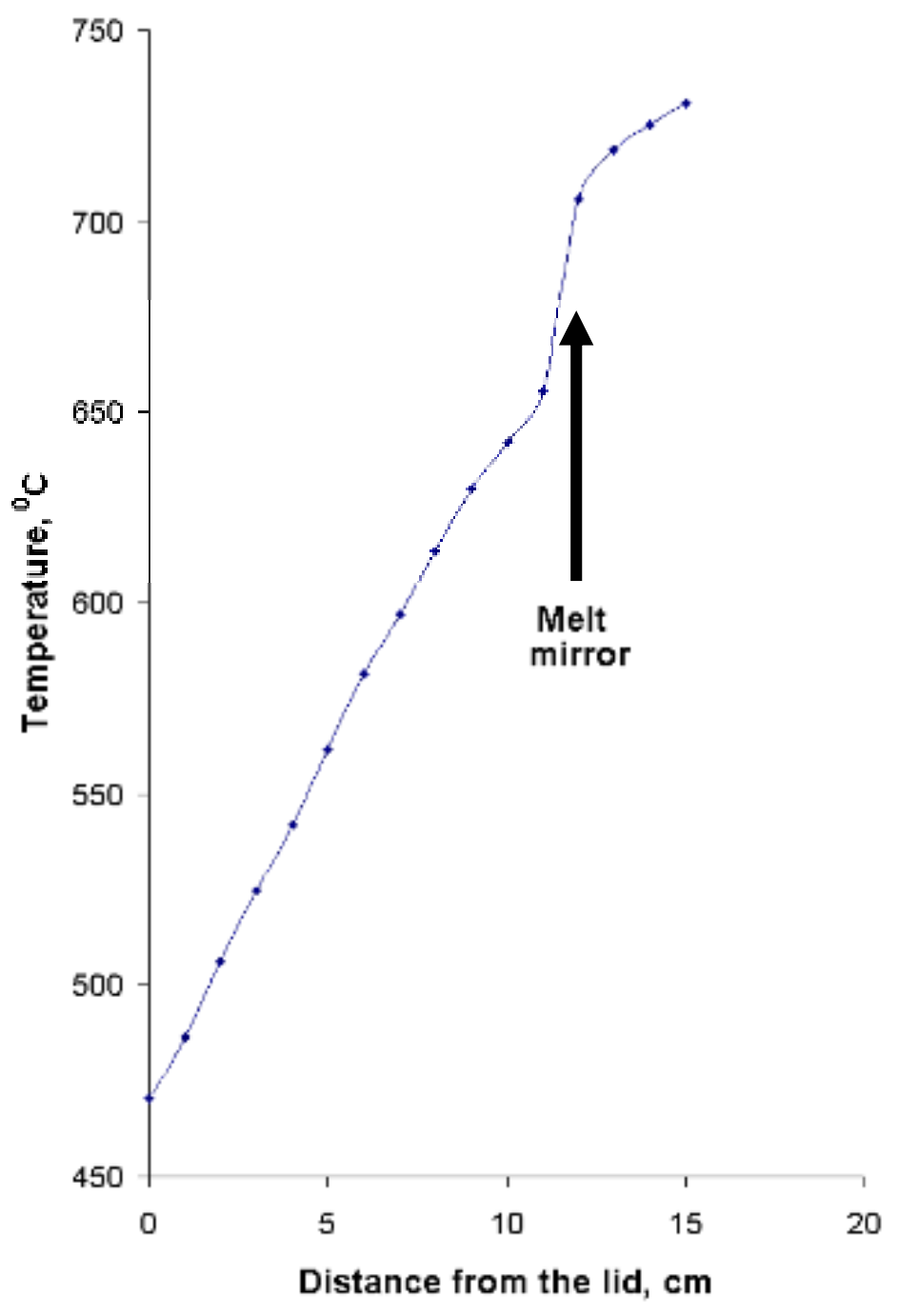

Figure 4. Temperature gradient of apparatus.

Therefore it can be concluded that the formation of the solid film on the melt surface is caused by not only slowness of the cathodic reduction reaction (or over-equilibrium concentration of $\mathrm{Nb}$ (III) ions) but also by the temperature gradient of the working zone of the apparatus. This problem can be eliminated by rising temperature or by increasing the height of the heated zone of the electrolyser.

To overcome the influence of significant temperature gradient at the melt surface the height of the hot zone of the cell was increased by increasing the working temperature by 50-100 degrees. This allowed stabilizing the anodic and cathodic current efficiencies (Table I, expts. 9-12). No film formation was observed on the melt surface during 8-10 
hours of the electrolysis. This temperature increase did not completely prevent the occurrence of the disproportionation reaction [5] (the cathodic current efficiency was still below the anodic) but limited it to the bulk of the melt.

\section{References}

1. M. J. Rand, US Patent No. 2939823 (1960).

2. V. G. Gopnienko and L. A. Pavlova, in Proc. VAMI (Trudy VAMI), 63, 108 (1968) (in Russian).

3. A. N. Baraboshkin, K. P. Lebedeva, N. A. Saltykova and V. K. Perevozkin, USSR Patent No. 173010 (1965).

4. A. N. Baraboshkin, N. A. Saltykova, M. I. Talanova and A. M. Molchanov, in Proc. IHTE UB AN USSR. Vol. 18, p. 87, Sverdlovsk (1972) (in Russian).

5. A. N. Baraboshkin, N. A. Saltykova, M. I. Talanova and A. M. Molchanov, in Proc. IHTE UB AN USSR. Vol. 19, p. 37, Sverdlovsk (1973) (in Russian).

6. A. N. Baraboshkin, N. A. Saltykova, O. N. Vinogradov-Zhabrov and A. M. Molchanov, USSR Patent No. 281993 (1970).

7. V. N. Storozhenko, in Proc. International Conf. on Theory of Processes of Nonferrous Metallurgy, p. 386, Alma-Ata (1971) (in Russian).

8. A. L. Glagolevskaya, S. A. Kuznetsova, E. G. Polyakov, S. V. Kuznetsova and P. T. Stangrit, Zh. Prikl. Khim., 61, 1036 (1988).

9. A. N. Baraboshkin, Electrocrystallization of Metals from Molten Salts, Nauka, Moscow, (1976) (in Russian).

10. I. B. Polovov, E. P. Kozlova, V. A. Volkovich, B. D. Vasin, L. F. Yamschikov, O. I. Rebrin and I. May, in EUCHEM 2006 Conference on Molten Salts and Ionic Liquids, Abstracts, p. 188, Hammamet, Tunisia (2006).

11. O. I. Rebrin, I. B. Polovov, A. S. Muhamadeev and A. V. Chernoskutov, Vestnik USTU-UPI, 35, 44 (2004).

12. A. S. Muhamadeev, PhD thesis, USTU-UPI, Ekaterinburg (2004) (in Russian). 